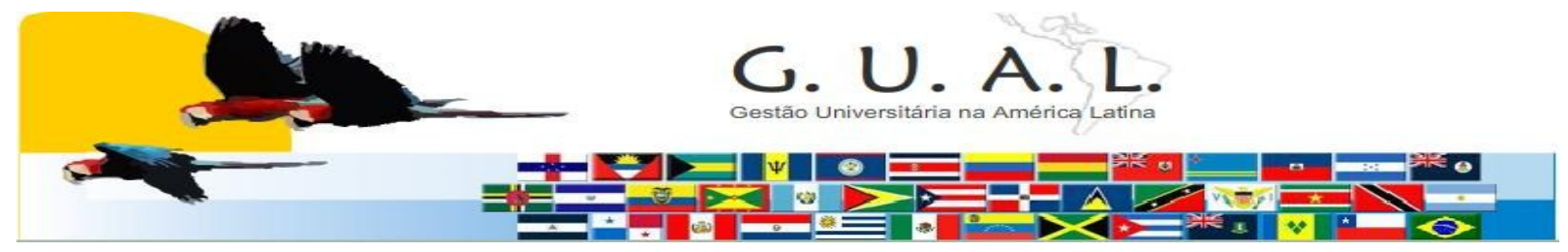

ISSN 1983-4535

\title{
A IMPORTÂNCIA DAS ATIVIDADES EXTRACURRICULARES UNIVERSITÁRIAS PARA O ALCANCE DOS OBJETIVOS PROFISSIONAIS DOS ALUNOS DE ADMINISTRAÇÃO DA UNIVERSIDADE FEDERAL DE SANTA CATARINA
}

\author{
Alessandra Knoll Pereira, Especialista \\ Universidade do Vale do Itajai - UNIVALI \\ alekawaii@gmail.com
}

\author{
Marcos Fernandes Koshino, Bacharel \\ Universidade Federal de Santa Catarina - UFSC \\ marcoskoshino@gmail.com
}

\author{
Talita Ribeiro Ferreira, Bacharel \\ Universidade Federal de Santa Catarina - UFSC \\ talitaferreira@gmail.com \\ Rudimar Antunes da Rocha, Doutor \\ Universidade Federal de Santa Catarina - UFSC \\ rrudimar@hotmail.com
}

\section{RESUMO}

Este artigo analisa a importância atribuída pelos alunos do curso de Administração da Universidade Federal de Santa Catarina às atividades extracurriculares para o alcance dos seus objetivos profissionais. O Objetivo geral configurou-se como: identificar como os alunos desse estudo avaliam a importância do desenvolvimento de atividades extracurriculares durante a vida acadêmica para o alcance dos seus objetivos profissionais; já os objetivos específicos foram: a) identificar as atividades extra-curriculares que os alunos consideram importantes para atingir os seus objetivos profissionais; b) identificar as aspirações profissionais dos ingressos e egressos; c) identificar se os ingressos e egressos planejam suas carreiras; d) verificar como a Instituição em estudo colabora com o oferecimento de atividades extra-curriculares; e) identificar quais as atividades que devem ser desenvolvidas para auxiliar o aluno em estudo na busca de sua realização profissional. Para tanto, esta pesquisa foi classificada como de caráter descritivo e qualitativo, e utilizou-se o método de pesquisa bibliográfica e a pesquisa de campo. Como instrumentos de coleta de dados foram utilizados questionários impressos e eletrônicos. Como resultado, tem-se a falta de orientação desses alunos sobre como selecionar as atividades extra-curriculares que poderão contribuir para o alcance dos seus objetivos profissionais, entre outros conclusões que serão apontados.

Palavras-chave: Empregabilidade. Planejamento de carreira. Administração universitária. 


\section{INTRODUÇÃO}

A escolha de um curso superior é para muitos jovens um dos maiores entraves e dilemas encontrados na sua vida. É basicamente a primeira grande escolha que as pessoas fazem durante a sua vida e essa decisão é muitas vezes influenciada pelas aspirações de seus pais, ou é baseada em tendências e carreiras em moda, ou até mesmo pela oportunidade ou também pela falta dela. Após escolher uma profissão e decidir as universidades para prestar o vestibular - exame para aprovação da entrada nos cursos superiores no Brasil - os jovens se deparam com outros dilemas; são tantas as atividades extracurriculares disponíveis durante a vida acadêmica que podem contribuir para o conhecimento específico em uma determinada área de estudo ou para o desenvolvimento de habilidades e competências, as quais contribuirão para o aperfeiçoamento de suas funções profissionais no mercado de trabalho.

Compreender como as atividades extracurriculares podem contribuir para o desenvolvimento desses estudantes durante o curso de graduação e para o alcance dos seus objetivos profissionais e contribuir para a sua inserção no mercado de trabalho desses novos profissionais pode ser uma maneira de facilitar a tomada de decisão dos alunos ingressantes. Aprender com a experiência dos egressos poderá ser uma forma de motivas os ingressos a se direcionarem para aquelas atividades extra-curriculares que exercerão maior impacto para o alcance dos seus objetivos profissionais.. Porém, poucas universidades dispõem de recursos que permitam a troca de experiências entre os ingressos e egressos e promovam o planejamento estratégico de carreiras antes e depois da graduação. Este estudo parte do pressuposto que os jovens universitários e recém-formados não utilizam o planejamento estratégico de carreira para nortear suas ações visando alcançar os seus objetivos profissionais. Acredita-se que identificar como os alunos desse estudo avaliam a importância da realização de atividades extra-curriculares para o seu desenvolvimento durante a vida acadêmica poderá contribuir para que a Universidade Federal de Santa Catarina desenvolva ações visando satisfazer as novas necessidades dos alunos de graduação em Administração frente às mudanças do ambiente externo. Partindo desse pressuposto, o objetivo do artigo é identificar como os alunos desse estudo avaliam a importância do desenvolvimento de atividades extracurriculares durante a vida acadêmica para o alcance dos seus objetivos profissionais.

Rev. GUAL., Florianópolis, Edição especial 2011, p.163-194. 


\section{A IMPORTÂNCIA DAS ATIVIDADES EXTRACURRICULARES UNIVERSITÁRIAS PARA O ALCANCE DOS OBJETIVOS PROFISSIONAIS DOS ALUNOS DE ADMINISTRAÇÃO DA UNIVERSIDADE FEDERAL DE SANTA CATARINA}

Para que o objetivo geral seja atingido, definiu-se como objetivos específicos: a) identificar as atividades extra-curriculares que os alunos consideram importantes para atingir os seus objetivos profissionais; b) identificar as aspirações profissionais dos ingressos e egressos; c) identificar se os ingressos e egressos planejam suas carreiras; d) verificar como a Instituição em estudo colabora com o oferecimento de atividades extra-curriculares que contribuem para a formação e preparação desses estudantes para o mercado de trabalho; e) identificar quais as atividades que devem ser desenvolvidas para auxiliar o aluno em estudo na busca de sua realização profissional. Portanto, busca-se com esse estudo responder à seguinte pergunta: quais as principais diferenças em relação à percepção dos ingressos e egressos do curso de Administração da Universidade Federal de Santa Catarina sobre a contribuição do desenvolvimento de atividades extra-curriculares para o alcance de seus objetivos profissionais no ano de 2010.

Com o intuito de responder à questão apresentada, o tema deste trabalho foi escolhido por diversos fatores. De acordo com a classificação de Castro (2006), as pesquisas podem ser justificadas de acordo com a sua importância, originalidade e viabilidade. Pra o autor, uma pesquisa é importante quando trata de um problema que afeta a sociedade ou a ciência. É original quando tem a capacidade de surpreender, não bastando o fato não ter sido demonstrada anteriormente. Por fim, uma pesquisa é viável quando o pesquisador tem a capacidade de concluir a pesquisa com êxito dentro do prazo, quando há base teórica suficiente, quando os dados existem e estão disponíveis e quando o pesquisador domina as ferramentas necessárias para a realização da pesquisa.

Apesar de terem sido encontrados outros trabalhos sobre o planejamento de carreira com alunos da UFSC, não foi encontrado trabalho algum que tenha entrevistado os alunos do curso de Administração, e especificamente os alunos ingressos e egressos. Portanto, este trabalho possuir originalidade, pois faz uma comparação entre o perfil dos alunos que ingressam e egressam do curso, possibilitando conhecer e confrontar as suas perspectivas.

Esta pesquisa mostra-se importante para diversos grupos, entre eles: a) a Universidade Federal de Santa Catarina, a qual poderá conhecer as atuais necessidades dos seus alunos em relação à preparação para o mercado de trabalho; b) ao Centro Sócio-Econômico que poderá expandir esses resultados para os outros cursos do mesmo centro; c) ao Departamento de Ciências da Administração que poderá tomar ações necessárias a suprir às necessidades 
desses alunos; d) aos prestadores de serviços de planejamento de carreira que conhecerão que tipo de cursos esses alunos apreciariam e; e) principalmente aos alunos do curso de Administração que poderão se basear no conhecimento e experiência dos egressos para tomarem suas decisões sobre que atividades extra-curriculares desenvolver para atingir seus objetivos profissionais. Em relação à viabilidade, esta pesquisa é viável, pois se adequa ao prazo estipulado para a sua realização, apresenta facilidade e meios de coleta de dados, por se tratar de uma população conhecida e de fácil acesso.

\section{FUNDAMENTAÇÃO TEÓRICA}

\subsection{As novas competências do administrador}

A economia mundial vem presenciando um período de transformações significativas marcadas principalmente pela intensa internacionalização das atividades econômicas. Fato que vem causando alterações econômicas, políticas e mundiais. Esse conjunto de transformações é conhecido por globalização e é influenciado por um conjunto de fatores que conjuga as políticas governamentais de abertura econômica e as forças independentes, comandadas pelo progresso tecnológico, como os avanços nas áreas de transporte e de comunicação (SILBER, 2006).

A globalização está relacionada ao aumento das relações e da interdependência entre países, gerando consequências que são vistas de forma positiva por uns e de forma negativa por outros (MARIOTTO, 2006). Porém, independentemente de como se percebe os impactos da globalização, é fato que ela não pode ser nem retardada, nem ignorada, pois,

as poderosas forças que a comandam, ligadas aos avanços tecnológicos em transporte e comunicações, têm vida própria e são independentes dos governos. Portanto, participar ou não da globalização não é uma escolha, dada as mudanças irreversíveis no ambiente internacional. Na era da tecnologia da informação, é impossível a um país isolar-se do mercado mundial, a não ser a um custo social muito elevado, já que ele se marginalizaria da prosperidade material aberta a um número crescente de nações (SILBER, 2006, p.23).

Friedman (2007) divide a globalização em três fases: a globalização 1.0, 2.0, 3.0. A primeira teve início em 1942, quando começou o comércio entre o velho e o Novo Mundo, o qual durou até cerca de 1800. Esse período da globalização foi marcado pela ação de países e

Rev. GUAL., Florianópolis, Edição especial 2011, p.163-194. 


\section{A IMPORTÂNCIA DAS ATIVIDADES EXTRACURRICULARES UNIVERSITÁRIAS PARA O ALCANCE DOS OBJETIVOS PROFISSIONAIS DOS ALUNOS DE ADMINISTRAÇÃO DA UNIVERSIDADE FEDERAL DE SANTA CATARINA}

governos que queriam se inserir na concorrência e aproveitar as oportunidades globais, motivados, em geral, pela religião, pelo imperialismo ou por uma combinação de ambos.

A globalização 2.0 ocorreu entre 1800 e 2000, com exceção dos anos em que se deu a Grande Depressão e as duas Grandes Guerras. Durante essa fase, os principais motores da globalização foram às empresas multinacionais, que se expandiram em busca de mercados de mão-de-obra. A integração foi impulsionada pelos avanços tecnológicos que reduziram os custos de transporte e de comunicação, o que, consequentemente, levou a um decréscimo nos custos de transação (SILBER, 2006).

A globalização 3.0 inicia-se por volta de 2000, encolhendo o mundo ainda mais. É nessa fase que ocorre a globalização dos indivíduos, a qual foi possível devido à convergência entre o computador pessoal, o cabo de fibra ótica e o aumento dos softwares de fluxo de trabalho.

Segundo Friedman (2007, p.21),

enquanto a globalização 1.0 foi a globalização dos países e, a globalização 2.0, a das empresas, na 3.0 a força dinâmica vigente (aquilo que lhe confere seu caráter único) é a recém descoberta capacidade dos indivíduos de colaborarem e concorrerem no âmbito mundial. [...] Pessoas do mundo inteiro começaram a acordar e perceber que tinha mais poder do que nunca para se tornarem globais como indivíduos, que precisavam mais do que nunca pensar em si próprias como indivíduos competindo com outros indivíduos em todo o planeta e que tinham amis oportunidades para trabalhar com esses outros indivíduos e não apenas para competir com eles.

Nesse contexto, os indivíduos passam a se questionar sobre como podem se inserir na concorrência global, como aproveitar as oportunidades que estão surgindo e como colaborar com outras pessoas em âmbito global. Mais uma vez, o avanço tecnológico se mostra de extrema importância, já que nos últimos anos houve uma disseminação de ferramentas e programas capazes de aproximar pessoas de diversos países, tais como o Facebook, o LinkedIn, o Twitter, entre outros. Esses sites de relacionamento permitem que as pessoas façam amigos de outras nacionalidades, mantenham esses contatos e se aproximem de realidades culturais completamente diferentes.

Em função de todas essas alterações no ambiente externo, muitas organizações passaram a buscar profissionais com essa capacidade de conviver em países diferentes, de inserir-se em outras culturas e comunicar-se em outros idiomas. Por essa razão tem-se 


\section{A IMPORTÂNCIA DAS ATIVIDADES EXTRACURRICULARES UNIVERSITÁRIAS PARA O ALCANCE DOS OBJETIVOS PROFISSIONAIS DOS ALUNOS DE ADMINISTRAÇÃO DA UNIVERSIDADE FEDERAL DE SANTA CATARINA}

observado nos últimos anos uma maior procura por programas de intercâmbio, sejam eles intermediados por empresas especializadas ou pela própria universidade. Percebe-se que o mercado de trabalho passa a exigir novas competências dos futuros profissionais e a adaptação dos atuais à esse novo contexto.

Para ser bem sucedido no planejamento de carreira, deve-se procurar analisar o mercado e perceber a demanda, ou seja, perceber que tipo de profissional está sendo procurado. Atualmente o perfil de profissional que está sendo valorizado tem habilidades e competências mais flexíveis e inovadoras. Assim, percebe-se que há todo um conjunto de novas competências que o profissional da atualidade deve procurar desenvolver, como ter um foco e planejamento, além de desenvolver a criatividade e inovação. Segundo o autor existe um novo perfil de funcionário, com espírito criativo, não conformado, que está sempre buscando melhorar.

Malschitzky (2004) também afirma que há um novo perfil de trabalhador, pois na virada do século até a atualidade a noção de emprego estável mudou, com as novas tecnologias, a reengenharia, o downsizing e etc. O autor ainda ressalta a importância de possuir uma gama de competências e desenvolver-se em diversas áreas, buscando um conhecimento mais generalista e amplo, permitindo uma atuação em diversos ramos de atividades (MALSCHITZKY, 2004).

Nota-se avaliando os pré-requisitos dos competitivos programas de trainee no Brasil que a criatividade é uma das características que está sendo muito procurada no profissional formado em Administração (CIA DE TALENTOS, 2010). Segundo Pereira (2010), há três componentes da criatividade: expertise, motivação e raciocínio criativo. A expertise é o conhecimento técnico e o intelectual; o primeiro é específico da área de atuação profissional; já o segundo conhecimento está relacionado às áreas que fogem ao conhecimento da sua área de atuação, como: conhecimento em poesia, música, cinema, etc. O segundo item, motivação intrínseca, é a perseverança aliada ao entusiasmo. E o último componente da criatividade, o raciocínio criativo, é composto por três diferentes habilidades: a fluência, a flexibilidade e a originalidade. Fluência é o número de ideias produzidas em relação a uma questão problema. Flexibilidade é o número de categorias diferentes em que as soluções dadas se enquadram. E, por fim, a originalidade é o número de respostas incomuns. O profissional que desenvolve a 


\section{A IMPORTÂNCIA DAS ATIVIDADES EXTRACURRICULARES UNIVERSITÁRIAS PARA O ALCANCE DOS OBJETIVOS PROFISSIONAIS DOS ALUNOS DE ADMINISTRAÇÃO DA UNIVERSIDADE FEDERAL DE SANTA CATARINA}

expertise e realiza um bom planejamento de carreira estará criando o futuro e não apenas se preparando para ele ou prevendo-se dele.

\subsection{Empregabilidade}

Com as mudanças tecnológicas que ocorrem mais rapidamente a cada dia, torna-se imprescindível a atualização de conhecimentos e o contínuo desenvolvimento de habilidades para manter as chances de atuação ampliadas. A segurança profissional que antigamente era garantida ao conseguir um emprego em uma organização na qual os profissionais passavam toda suas vidas não é mais uma realidade no contexto do mercado de trabalho brasileiro.

Empregabilidade é a "condição de ser empregável, isto é, de dar ou conseguir emprego para os seus conhecimentos, habilidades e atitudes intencionalmente desenvolvidas por meio de educação e treinamento sintonizados com as novas necessidades do mercado de trabalho" (MINARELLI, 1995, p.11). Dessa forma, cuidar da sua empregabilidade é uma forma de se ajudar nesses novos tempos, quando o tempo de permanência nas empresas diminui e a rotatividade aumenta.

De acordo com Minarelli (1995, p. 20) os profissionais precisam estar aptos do ponto de vista técnico, gerencial, intelectual, humano e social para solucionar com rapidez problemas cada vez mais sofisticados e específicos e, além disso, o mercado valoriza dá preferência a profissionais com múltiplas habilidades e com iniciativa. Desta forma, percebese a necessidade de desenvolver habilidades de todos os aspectos durante a vida acadêmica e não somente foca-se na capacitação técnica e profissional proporcionada pelos estudos para a obtenção do grau de bacharel em Administração.

Quanto mais intensas a vida e a atuação profissional, maior é o estoque de informações que as pessoas acumulam em sua bagagem e isso, segundo Minarelli (1995), tem um valor inimaginável. Conforme muitos autores apontam, percebe-se que com a globalização e as mudanças nas organizações, exigem-se novas competências para o administrador nesse novo mercado de trabalho.

A diminuição das ofertas de emprego é uma consequência das transformações que ocorreram no mundo do trabalho nas últimas décadas. Até meados dos anos 70 do século XX, o trabalho nos países desenvolvidos apresentava-se relativamente estruturado em sua forma de emprego, com razoável distribuição de renda, baixos níveis de desemprego e inflação. Esse

Rev. GUAL., Florianópolis, Edição especial 2011, p.163-194. 
funcionamento foi rompido pela mundialização da economia e pelo acirramento da competição entre as organizações. $O$ padrão de desenvolvimento utilizado até então - taylorismo/fordismo - mostrou sinais de esgotamento. Para manter a expansão do capital, as empresas investiram em mudanças que disponibilizassem a redução dos custos de produção e a melhoria da qualidade dos produtos e serviços, resultando no processo de reestruturação produtiva (VEREGUINE, 2008, p.26)

Portanto, nos dias atuais é mais difícil manter-se empregado e esse contexto emerge entre os empresários o conceito de empregabilidade, que se refere à "capacidade individual de obter emprego ou se manter empregado" (VEREGUINE, 2008, p.28).

Com o conceito de empregabilidade fica claro que o profissional deve ser um ator da sua própria carreira, ou seja, ele deve se preparar para o mercado e não esperar passivamente por uma vaga. "Se antes a manutenção do emprego era responsabilidade da sociedade e do empregador, no contexto da empregabilidade, ela passou a ser responsabilidade unicamente do indivíduo (VEREGUINE, 2008, p.28).

As rápidas mudanças têm favorecido o surgimento cada vez mais rápido de novas profissões e ocupações. De acordo com o Ministério do Trabalho e Emprego - MTE (2010), em 2010 houve 100 atualizações na lista de Classificação Brasileira de Ocupações - CBO.

A atualização e modernização do documento ocorreram para acompanhar as mudanças econômicas, sociais e culturais pelas quais o Brasil passou nos últimos anos, que implicaram modificações estruturais no mercado de trabalho. Entre as principais atualizações estão a inclusão de novas categorias de tecnólogos, com 87 títulos, e a inclusão dos profissionais da saúde da família, para atender a uma demanda do Ministério da Saúde (MET, 2010).

De acordo com Vereguine (2008, p.13), “grande parte da organização da vida social baseia-se na preparação para a entrada no mundo do trabalho e na posterior atuação como profissional". Frente a essas diversas mudanças, além do mercado de trabalho, as instituições de ensino superior também têm buscado se adaptar a esse novo contexto. Desde 1999, o número de cursos nessas instituições tem evoluído conforme o gráfico 1.

O novo contexto do mundo do trabalho marcado pela reestruturação produtiva, pela flexibilização, pela precarização do trabalho, pelos altos índices de desemprego e pela exigência de um novo perfil de trabalhador mais "qualificável" e "empregável" vem gerando modificações no conceito e no desenvolvimento das carreiras (VEREGUINE, 2008, p.29). 


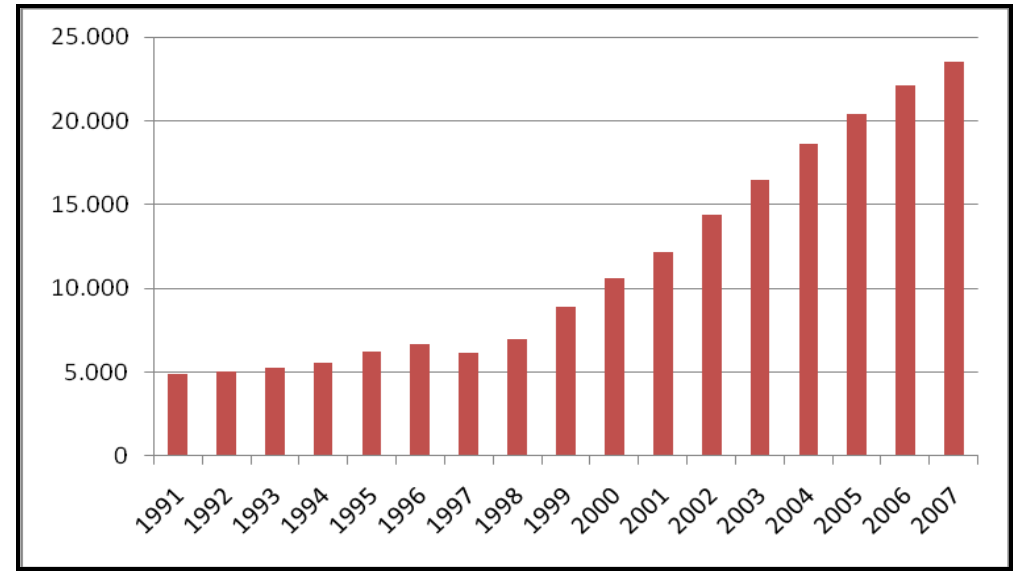

Gráfico 1 A evolução do número de cursos em instituições de ensino superior no Brasil (1991-2007) Fonte: INEP (2007).

Ou seja, esta flexibilidade que tem seus aspectos positivos (horários diferenciados, home office, mais espaço para criatividade, etc.) acaba por outro lado gerando uma insegurança no profissional que não tem mais a garantia de estabilidade que era comum no século passado:

Ao longo dos anos, a carreira adquiriu diferentes enfoques, de acordo com as mudanças que ocorreram no mundo do trabalho. Até recentemente, quando predominava o modelo de produção taylorista/fordista, a ideia de carreira era associada diretamente ao emprego e à permanência numa estrutura organizacional. A carreira era a movimentação de ascensão linear e vertical que a pessoa realizava ao longo do organograma de uma mesma empresa. Escolhia-se uma profissão na juventude, e a carreira não sofria muitas alterações (VEREGUINE, 2008, p.32).

Não apenas o conhecimento está mais dinâmico, com mais descobertas e novas tecnologias que são atualizadas num ritmo frenético, mas a carreira também está mais dinâmica. Os jovens que visam ingressar no mercado de trabalho devem estar preparados para estes desafios e saber aproveitá-los a seu favor. Observa-se hoje que muitos indiv]iduos começam a gerir suas próprias carreiras ao invés de deixá-la a cargo da empresa para a qual trabalha.

Dessa forma o individuo é colocado numa posição mais decisiva de sua própria vida e carreira. Se antes a carreira começava já cedo e não exigia grandes desafios ou mudanças até a aposentadoria, atualmente o modelo de carreira pressupõe escolhas, decisões muito maiores por parte do profissional, pois pode-se mudar de emprego com mais frequência ou ser 


\section{A IMPORTÂNCIA DAS ATIVIDADES EXTRACURRICULARES UNIVERSITÁRIAS PARA O ALCANCE DOS OBJETIVOS PROFISSIONAIS DOS ALUNOS DE ADMINISTRAÇÃO DA UNIVERSIDADE FEDERAL DE SANTA CATARINA}

demitido e acabar reformulando seu projeto de vida. Com a flexibilidade do mercado há chance do profissional ser seu próprio ator, fazer sua própria cena e escolha.

Se o profissional é agora o centro das decisões e tem mais controle e flexibilidade sobre sua carreira, torna-se de extrema relevância o autoconhecimento e o planejamento estratégico de carreira.

\subsection{Planejamento de carreira}

Minarelli (1995) acredita que para conquistar a segurança profissional e financeira, a autogestão da carreira e a construção de bases próprias são os complementos à capacidade técnica. $\mathrm{O}$ autor também define seis pilares que sustentam a construção de bases próprias: a competência profissional, a idoneidade, a saúde física e mental, a reserva financeira, a adequação vocacional e as fontes alternativas e relacionamentos.

Minarelli (1995, p.13) aponta o check-up profissional e pessoal como uma forma de avaliar as "armas e bagagem" e para avaliar a segurança profissional. $\mathrm{O}$ autor também propõe oitenta e oito questões para fazer esse check-up de vida e carreira que servem de base para o auto-diagnóstico para que finalmente se possa fazer um plano de ação para incrementar a empregabilidade e, consequentemente, a carreira. São raros os profissionais que se preocupam em verificar periodicamente como estão os seus conhecimentos, habilidades e experiências, principalmente quando estão bem empregados.

A cada dia torna-se mais importante para o profissional a condução de sua própria carreira. Não é mais possível que apenas as empresas se preocupem com a carreira de cada colaborador, uma vez que as competências de cada indivíduo devem ser desenvolvidas de acordo com a sinalização do mercado e a aplicabilidade dessas competências, as quais poderão ser aplicadas em várias organizações. É preciso criar e manter a empregabilidade. $\mathrm{O}$ desenvolvimento da especialidade (cursos de graduação e pós-graduação) deve ser seguido por conhecimentos ecléticos que permitam atuar profissionalmente em diversas frentes de trabalho, tanto técnico como gerencial (MALSCHITZKY, 2004).

Uma vez escolhido o curso superior, os alunos da graduação já podem planejar suas carreiras. Esse planejamento pode iniciar-se planejando as disciplinas optativas a serem escolhidas, as atividades extra-curriculares a serem desenvolvidas, os cursos de idiomas e 
muitas outras possibilidades de desenvolvimento pessoal e profissional que são oferecidas nas universidades. Corroborando esse ponto, Malschitzky (2004) afirma que

\begin{abstract}
esse planejamento pode ser elaborado ainda na fase acadêmica, onde o aluno poderá prospectar seus anseios em termos de vivenciar a teoria aprendida em empresas que disponibilizam oportunidades de estágios. Concomitantemente a isso, também terá a oportunidade de planejar o desenvolvimento de comportamentos e atitudes apropriados para o relacionamento interpessoal. Para tanto, deverá participar de cursos extra-curriculares que possibilitem a preparação adequada para o ambiente de trabalho, utilizando-se de técnicas específicas para comunicar-se com a equipe, relacionar-se, apresentar-se, desenvolver habilidades de gestão (liderança) e outras que o mercado exige. Quanto mais ações de desenvolvimento pessoal e profissional e conhecimento agregado ele absorver, maior poderá ser a chance de encontrar uma posição vantajosa quando se trata de ingressar ou se manter num emprego.
\end{abstract}

Assim, o aluno deveria ter um acompanhamento para o desenvolvimento da carreira para que consiga focar em trabalhos que estimulem ou exijam suas as capacidades inatas ou talentos, bem como, identifique seus pontos fracos, os quais devem ser melhorados através de atividades como estágio, por exemplo.

O planejamento estratégico é recente, porém há livros utilizados neste tema escritos há muito tempo, como a arte da guerra de SunTzu (escrito há cerca de 2400 anos). Mintzberg (2006) ao definir o que é planejamento, destaca cinco sentenças, mostrando a evolução deste pensamento: (1) planejamento é pensar no futuro; (2) planejamento é controlar o futuro; (3) planejamento é tomada de decisão; (4) planejamento é tomada de decisão integrada; e (5) planejamento é um processo formal para produzir um resultado articulado, na forma de um sistema integrado de decisões. É essencial que o aluno tenha a visão de que a sua carreira é um bem, um investimento, que precisa de planejamento estratégico.

\title{
2.3.1 Planejamento estratégico de carreira
}

Diante da competitividade do mercado, faz-se necessário um diferencial competitivo, que pode ser um bom planejamento de carreira.

Uma vez que o planejamento de carreira demanda a escolha pela forma como o indivíduo quer atuar profissionalmente, a situação de complexidade do mercado de trabalho surge como uma variável importante que pode dificultar a reflexão sobre o futuro da carreira. Ao perceber a dificuldade de

Rev. GUAL., Florianópolis, Edição especial 2011, p.163-194. 
inserção, o jovem universitário pode abandonar seu sonho profissional para se adaptar às exigências mercantis (VEREGUINE, 2008, p.14).

Dutra (1996, p.53) ressalta que o plano de carreira é associado a uma idéia de estrada plana, bem conservada e asfaltada, que, "se bem trilhada pela pessoa, a conduzirá ao sucesso, à riqueza e à satisfação profisssional”.

A idéia tradicional de planejamento de carreira deriva da administração e se baseia nos modelos de planejamento estratégico. Como uma empresa, a pessoa deve avaliar o ambiente interno e externo, elaborar os objetivos e traçar as estratégias de ação, tendo como base a "missão", a "visão" e os valores pessoais. Nessa concepção, o planejamento de carreira é o ato ou o processo de estabelecer objetivos, diretrizes e procedimentos para a realização de uma ou de várias metas profissionais (VEREGUINE, 2008, p.30).

Algumas pessoas ainda deixam a responsabilidade pela gestão de carreira a cargo da empresa para a qual trabalha, outros acreditam que a ascensão na carreira é uma questão de sorte ou mudar de empresa para empresa. Segundo Dutra (1996) haveria um idealização da gestão compartilhada da carreira entre a empresa e as pessoas. Hall (1976, apud DUTRA, 1996), acredita que as resistências existente nas pessoas e nas empresas em relação à gestão de carreiras serão cada vez menores na medida em que essas pessoas se sintam pressionadas a revisar suas posições em relação a suas carreiras.

Os jovens que estão a caminho da entrada no mercado de trabalho parecem desconhecerem as finalidades do plano de carreira. Oliveira (2009) relaciona as que são consideradas por ela como principais: a) dar foco de direcionamento profissional para as pessoas; b) facilitar a interligação entre conhecimentos diversos; c) facilitar, se necessário, a alteração do rumo profissional; d) dar mais segurança para as pessoas; e) propiciar amplo debate da vida profissional das pessoas.

Por essas e outras razões, percebe-se que muitos autores afirmam o autoconhecimento como um fator decisivo para o alcance dos objetivos profissionais.

\subsubsection{Autoconhecimento como fator decisivo no planejamento estratégico de carreira}

Conhecer suas forças e fraquezas facilita o processo de autoconhecimento para a elaboração de um planejamento estratégico de carreira adequado. "O autoconhecimento refere-se ao conhecimento sobre si mesmo e pode ser definido como as informações que uma 
pessoa possui sobre seu modo de ser e a maneira como geralmente se comporta" (VEREGUINE, 2008, p.35). O autoconhecimento facilitará a identificação de verdadeiras oportunidades de desenvolvimento profissional e das suas aptidões, talentos e ambições.

Embora o modelo emergente de carreira possibilite certa liberdade de
escolha, é importante compreender que essa liberdade é sempre
condicionada ao contexto social e econômico e às condições impostas pelo
sistema capitalista vigente. Todo indivíduo escolhe a partir das condições
que o meio material lhe possibilita (VEREGUINE, 2008, p.33).

Desta forma, deve-se estar ciente de quem se é para saber onde se pode chegar e o que é preciso para isso, por isso o autoconhecimento torna-se relevante. De acordo com Greca (2000, p.116), “o ser humano, como um ser relacional, tem que ter (conhecer) a noção de sua história, de sua experiência passada como referência para sua ação no presente e assim moldar seu futuro de acordo com seus desejos e suas capacidades".

É neste contexto que se revela importante o planejamento de carreira. Vereguine (2008, p. 33) afirma que "o planejamento de carreira dentro do modelo emergente e do atual contexto do trabalho exige do indivíduo, mais do que no modelo tradicional, a capacidade de realizar escolhas e tomar decisões". Desta forma, o planejamento estratégico de carreira apresenta-se como uma ferramenta utilizada para atingir os objetivos profissionais e a satisfação pessoal, através do conhecimento de suas capacidades e necessidade de desenvolvimento visando facilitar a tomada de escolhas coerentes com suas aspirações.

\subsection{O papel da universidade na formacao profissional}

A universidade hoje é uma peça importante no mercado profissional brasileiro, pois o curso superior continua sendo um diferencial. Aulas presenciais e a distância, atividades extracurriculares, iniciação científica, laboratórios, pós-graduação entre outras, são atividades oferecidas por universidades em todo Brasil que agregam muito na formação profissional.

A universidade tem um papel fundamental na formação profissional do seu aluno, primeiramente, o mínimo que se espera da universidade e que ela proporcione ao aluno capacidade de, com os conhecimentos adquiridos em sala de aula, se adequar ao mercado de trabalho, capacidade técnica, então e o requisito primário que uma faculdade deve fornecer ao aluno.

Rev. GUAL., Florianópolis, Edição especial 2011, p.163-194. 
Para os jovens universitários, há uma grande distância entre o que é ensinado na graduação e o que o mundo do trabalho exige. Grande parte do conteúdo dos cursos é de cunho teórico, e não prático, o que na opinião dos entrevistados dificulta a aplicação do conhecimento na vida profissional (VEREGUINE, 2008, p.96).

Ao mesmo tempo em que a faculdade deve oferecer um bom conteúdo técnico profissional, ela não pode se limitar a apenas isso, devendo também, formar além do técnico ou especialista, mas deve também proporcionar o desenvolvimento da capacidade crítica e construtiva do aluno, para que esse não seja apenas um mero repetidor de conceitos mas além disso tenha bem desenvolvida a capacidade analítica de ver e compreender a realidade e a si mesmo de forma muito maior e mais reflexiva.

Um objetivo da educação universitária é sem dúvida a formação de mão-deobra especializada. No entanto, como campo de ensino e aprendizagem, um curso de graduação tem objetivos muito mais amplos que a simples preparação para o mercado de trabalho. Uma graduação deve preparar o profissional para uma postura crítica e inovadora diante da realidade (VEREGUINE, 2008, p. 98).

Desta forma, a universidade tem um papel fundamental na formação pessoal e profissional do aluno, eis que as duas estão extremamente ligadas, já que quanto maior o autoconhecimento do profissional melhor será sua capacidade de realizar um planejamento de carreira compatível com o mercado e com os seus objetivos profissionais e pessoais e, dessa forma, serão maiores, consecutivamente, as chances de ser bem sucedido em suas metas e objetivos. Assim, é papel da universidade oferecer atividades extra-classe que tenham como objetivo capacitar o aluno a desenvolver um melhor raciocínio crítico e uma adequada percepção de si, da realidade, do mercado e de sua projeção profissional

Muito mais do que simples receitas de como fazer, é preciso que o ensino desenvolva habilidades de reflexão e produção de conhecimentos, sejam eles teóricos ou práticos. É preciso que o jovem profissional consiga processar os conteúdos aprendidos de forma a ser capaz de agir diante das diversas realidades do mundo do trabalho (VEREGUINE, 2008, p.98).

Assim, mostra-se de extrema relevância as atividades extra-curriculares na formação de um aluno mais completo e com melhor capacidade de análise, pois é através dessas 
atividades e do autoconhecimento adquirido através delas (também) que o individuo chega ao seu perfil de profissional

Primeiro, o indivíduo atravessa o processo de escolha por uma profissão; em seguida, adquire conhecimento na formação acadêmica; depois aplica o conhecimento na prática profissional. Ao longo de sua trajetória, emergem diferentes movimentos e situações em seu fazer profissional que vão pouco a pouco construindo a identidade profissional do sujeito. Quando ele adquiriu plena consciência de seu exercício profissional, todas as etapas anteriores são integradas na identidade profissional. Embora haja uma seqüência, ela não é estanque e nem linear, ocorre de maneira singular na vida de cada pessoa. À medida que o sujeito experiência atividades, ele vai se transformando dialeticamente. Sua percepção do mundo, seus valores, sua ética e sua postura diante da vida são transformados conforme os ditames de sua profissão. Por meio do fazer, a pessoa constrói, desconstrói e reconstrói uma série de significados para seu trabalho e para sua vida (VEREGUINE, 2008, p.41-42).

Neste contexto, as atividades extra-curriculares têm um papel relevante para aumentar a capacidade analítica do aluno, seu autoconhecimento, no desenvolvimento de sua identidade profissional.

\subsubsection{A evolução do marketing até o marketing de relacionamento}

O esforço para levar a produção para o consumidor ou usuário é observado há milhares de anos, mas foi depois da revolução industrial, devido ao volume produzido e a uma nova percepção de valor, que começou a ser pesquisado, conceituado e otimizado. A logística e produtividade para a maximização de lucros era a primeira preocupação do marketing.

Pode-se percebera evolução histórica do conceito de marketing analisando o conceito apresentado pela American Marketing Association: "a realização de atividades de negócios dirigidas ao fluxo de bens e serviços do produtor ao consumidor ou usuário" (AMA, 1948 apud WOOD, 1997, p.4). Anos mais tarde, a mesma organização atualizou seu conceito, definindo-o como "o processo de planejar e executar a concepção, definição de preço, promoção e distribuição de ideias, bens e serviços para criar trocas que satisfaçam os objetivos individuais e organizacionais" (AMA, 1948 apud WOOD, 1997, p.4). Porém, essa definição, para Wood (1997), não reconhecia o valor de se construir e administrar um relacionamento com o consumidor ou usuário. Portanto, esse autor define marketing como o 


\section{A IMPORTÂNCIA DAS ATIVIDADES EXTRACURRICULARES UNIVERSITÁRIAS PARA O ALCANCE DOS OBJETIVOS PROFISSIONAIS DOS ALUNOS DE ADMINISTRAÇÃO DA UNIVERSIDADE FEDERAL DE SANTA CATARINA}

processo de estabelecimento e manutenção das relações de troca mutuamente benéficas com clientes e outros grupos de interesse.

Para Kotler (2007), outro autor que define o mesmo termo, marketing significa conquistar e manter clientes. Também é a ciência de descobrir como fazer algo vender melhor. Marketing, na visão de Kotler (2007), é a análise, organização, planejamento e controle dos recursos da empresa, os quais são gerados a partir do consumidor, com o objetivo de satisfazê-lo em suas necessidades e desejos, de forma lucrativa.

As ações de marketing envolvem toda a vida do produto ou serviço, desde o momento em que ele é apenas uma ideia, invenção, ou projeto ou simples demanda do consumidor detectada em pesquisa, até o consumo, incluindo as etapas de pós-venda (atendimento ao consumidor ou contratação de serviços), afirma Kotler (2007). Isso implica conhecer o que o consumidor deseja estudar a produção desta necessidade (desse bem de consumo); produzi-la, distribuí-la e vendê-la ao consumidor, inclusive ensinando-lhe a consumidor o produto. Através do marketing, procura-se satisfazer as necessidades de consumo e criar novas necessidades.

Wood (1997, p.4) aborda a troca de marketing como sendo mutuamente benéfica, ao afirmar que "o marketing não ocorre a não ser que exista uma troca, a ação de comercializar ou vender alguma coisa de valor". Hoje a palavra marketing, segundo Giuliani (2003), é utilizada tratar de um grande número de ações e atividades relacionadas ao mercado.

A percepção de que o marketing não é somente um composto de atividades que visam à troca do produto por um valor, tendo como agentes o consumidor e o produtor é bem recente. Diversos autores dizem que o relacionamento deve estar sempre presente nesse conceito. Para Wood (1997, p.5), o marketing de relacionamento é o "processo de estabelecer e manter relacionamentos de longo prazo", mas sempre visando a criação de relacionamentos que sejam mutuamente benéficos entre organizações e seus clientes, empregados e outros grupos de interesse. O marketing de relacionamento estabelece sólidas ligações econômicas, técnicas e sociais entre as partes. Ele reduz o dinheiro e o tempo investidos nas transações. Nos casos mais bem sucedidos, as transações deixam de ser negociadas de tempos em tempos e se tornam rotineiras (KOTLER, 2000, p.35).

Com a definição do conceito de marketing de relacionamento e a evolução de marketing fica claro a necessidade da utilização de práticas de marketing de relacionamento 
em todas as organizações, inclusive nas organizações de ensino como faculdades particulares, escolas, colégios e universidades públicas e privadas.

\subsubsection{O marketing de relacionamento da UFSC}

O marketing de relacionamento da Universidade Federal de Santa Catarina tem como principal objetivo a construção e manutenção de um relacionamento com o seu principal cliente, os estudantes. Faz parte dessa construção o oferecimento de diversos serviços como a Biblioteca Universitária, o Restaurante Universitário, o Laboratório de Informática, a Moradia Estudantil, entre outros. A UFSC ainda apoia e fomenta projetos como Centros Acadêmicos Estudantis, Empresas Juniores e eventos. Todas essas ações têm como objetivo estreitar a relação entre o aluno e a universidade. A UFSC ainda possui ainda um portal de egressos que por objetivo manter um vínculo contínuo seus ex-alunos, saber de seus sucessos e dificuldades, e acompanhar os profissionais que são formados por ela e ingressam no mercado de trabalho. Dessa forma, a universidade visa melhorar seus cursos a cada ano, e direcionar seus projetos de formação continuada às necessidades dos profissionais de cada área (UFSC, 2010a).

\subsubsection{Ações e atividades desenvolvidas na UFSC que contribuem para a empregabilidade dos seus alunos}

Segundo o site da Universidade Federal de Santa Catarina, a UFSC tem por finalidade

produzir, sistematizar e socializar o saber filosófico, científico, artístico e tecnológico, ampliando e aprofundando a formação do ser humano para o exercício profissional, a reflexão crítica, solidariedade nacional e internacional, na perspectiva da construção de uma sociedade justa e democrática e na defesa da qualidade de vida (UFSC, 2010b).

Os alunos e usuários da universidade dispõem de um leque gigantesco de oportunidades para se desenvolver e buscar novas competências. Hoje a UFSC conta com 14 empresas júniores e outras diversas organizações como a AIESEC, as quais contribuem para o desenvolvimento pessoal e profissional dos seus participantes.

Núcleos de pesquisa e laboratórios também oferecem oportunidades para produzir, sistematizar e socializar o saber filosófico, científico, artístico e tecnológico. Eles estão 
presentes em todos os centros de ensino da UFSC e oferecem a oportunidade dos alunos participarem diretamente em projetos de pesquisa e desenvolvimento do conhecimento.

\section{METODOLOGIA}

O procedimento metodológico utilizado para realizar esta pesquisa é apresentado quanto à caracterização do estudo, coleta e análise de dados e às limitações da pesquisa. A pesquisa caracteriza-se, de acordo com Mattar (2001) como descritiva, pois expõe as características e uma determinada população sem o objetivo de explicá-los. Vergara (2007) afirma que esse tipo de pesquisa expõe características de determinada população ou determinado fenômeno. Em relação aos meios de investigação, Vergara (2007) classifica as pesquisas em pesquisa de campo, pesquisa de laboratório, documental, bibliográfica, experimental, ex post facto, participante, pesquisa-ação e estudo de caso. Dessa forma, esta pesquisa se caracteriza como uma pesquisa de campo, a qual é definida por Vergara (2007) como uma investigação empírica realizada no local que dispõe de elementos para explicar um fenômeno e permite incluir a aplicação de questionários. Mattar (2001) ressalta que a pesquisa de campo busca levantar dados representativos sobre a população de interesse, gerando tabelas com os dados coletados e cruzamentos entre eles.

No que se refere à coleta de dados primários esta pesquisa se caracteriza como por comunicação, estruturada e não disfarçada, realizada através de questionários autopreenchidos que foram enviados por meio eletrônico aos sujeitos da pesquisa passíveis de acesso via correio eletrônico e pessoalmente. A pesquisa também foi descritiva conclusiva, pois, segundo Mattar (1996) a pesquisa conclusiva se caracteriza por seus objetivos bem definidos.

No que se refere à natureza das variáveis pesquisadas, esta pesquisa se caracteriza como quantitativa de acordo com Mattar (1996), pois os dados são obtidos de muitos respondentes, usando-se escalas numéricas, o que possibilita submetê-los à análise estatística a fim de correlacioná-los e interpretá-los.

A coleta de dados é definida por Barros e Lehfeld (2007, p.105) como "a fase da pesquisa em que se indaga a realidade e se obtém dados pela aplicação de técnicas". Este trabalho, baseou-se principalmente na coleta de dados primários. Porém, dados secundários foram verificados principalmente na fase de leitura exploratória, a qual precedeu a aplicação 


\section{A IMPORTÂNCIA DAS ATIVIDADES EXTRACURRICULARES UNIVERSITÁRIAS PARA O ALCANCE DOS OBJETIVOS PROFISSIONAIS DOS ALUNOS DE ADMINISTRAÇÃO DA UNIVERSIDADE FEDERAL DE SANTA CATARINA}

de questionários. $\mathrm{Na}$ fase de coleta de dados primários utilizou-se como principal instrumento o questionário. Segundo Vergara (2007), o questionário é caracterizado por agrupar uma série de questões escritas. Estas questões podem ser abertas ou fechadas, ou seja, podem obter respostas livres ou podem obter respostas de acordo com as alternativas apresentadas.

Dentre as vantagens da aplicação de questionário pode-se destacar a maior facilidade em tabular e tratar os dados coletados, a garantia de anonimato do respondente e a economia de tempo e recursos financeiros e humanos em sua aplicação (BARROS; LEHFELD, 2007). O questionário desenvolvido apresenta principalmente questões fechadas, porém algumas permite ao respondente mencionar um alternativa que não foi apresentada pelos pesquisadores.

Após o questionário ter sido concluído foi realizado um pré-teste. Primeiramente com colegas da disciplina e em seguida foi feita uma análise pelo professor orientador a fim de adequar o instrumento aos objetivos propostos para a pesquisa.

O grupo de sujeitos analisados nessa pesquisa foram os ingressos e egressos do curso de Administração da Universidade Federal de Santa Catarina no ano de 2010. Foram enviados através de e-mail 304 questionários, 200 para ingressos e 104 para os egressos, alunos do curso noturno e diurno. Esses sujeitos foram determinados de acordo com sua matrícula em disciplinas obrigatórias para os estudantes que se encontram no início ou término do curso. Além disso, alguns questionários foram aplicados pessoalmente, devido ao baixo índice de respostas via correio eletrônico. Ao final, totalizou-se 99 questionários respondidos pelos ingressos e 41 pelos egressos, perfazendo uma amostra de 140 respondentes de uma população alvo de 304 pessoas. O envio dos questionários pela forma on line foi realizada pela Coordenadoria do Curso de Administração, com pedido do professor orientador da pesquisa. A composição da amostra foi elaborada de forma não-probabilística pelo critério de acessibilidade e foram aceitos somente os questionários respondidos corretamente. Vergara (2007) explica que uma amostra probabilística por acessibilidade é aquela que, longe de qualquer procedimento estatístico, seleciona elementos pela facilidade de acesso a eles. Entretanto, Barbetta (2005, p.25) salienta que "os resultados da pesquisa serão válidos para este conjunto de elementos". Portanto os resultados desta pesquisa só serão válidos para os ingressos e egressos do curso de Administração da UFSC de 2010.

Rev. GUAL., Florianópolis, Edição especial 2011, p.163-194. 
Quanto às limitações da pesquisa, esta foi limitada pelo acesso às informações, devido a um número pequeno de respostas (atingindo quase metade da população alvo). Houve um número pequeno de respostas pelo meio eletrônico, o que foi resolvido, em partes, pelos questionários respondidos pessoalmente (na sala de aula). Ocorre que os egressos do primeiro semestre de 2010 não foram contatados pessoalmente, apenas pelo meio eletrônico, o que resultou em menos respostas dos egressos que dos ingressos.

\section{RESULTADOS E ANÁLISE DE DADOS}

Inicialmente, foram analisadas as respostas buscando identificar os itens que tiveram maior destaque por um alto índice de respostas. Percebe-se que, em ambos os casos (egresso e ingressos), a principal atividade desenvolvida é a dedicação aos estudo universitário.

Tabela 1: Principal atividade profissional

\begin{tabular}{|c|c|c|c|c|c|c|}
\hline \multirow[t]{2}{*}{ Qual a sua principal atividade "profissional" no momento? } & $\begin{array}{c}\text { Frequência } \\
\text { absoluta }\end{array}$ & $\begin{array}{c}\text { Frequência } \\
\text { relativa }\end{array}$ & \begin{tabular}{|c|} 
Frequência \\
relativa \\
acumulada \\
\end{tabular} & $\begin{array}{c}\text { Frequência } \\
\text { absoluta }\end{array}$ & $\begin{array}{l}\text { Frequência } \\
\text { relativa }\end{array}$ & $\begin{array}{l}\text { Frequência } \\
\text { relativa } \\
\text { acumulada }\end{array}$ \\
\hline & \multicolumn{3}{|c|}{ Ingressos } & \multicolumn{3}{|c|}{ Egressos } \\
\hline À procura de emprego & 1 & $1 \%$ & $1 \%$ & 3 & $7 \%$ & $7 \%$ \\
\hline Estudante & 75 & $76 \%$ & $77 \%$ & 15 & $37 \%$ & $44 \%$ \\
\hline Funcionário público & 5 & $5 \%$ & $82 \%$ & 6 & $15 \%$ & $59 \%$ \\
\hline Profissional liberal & 0 & $0 \%$ & $82 \%$ & 3 & $7 \%$ & $66 \%$ \\
\hline Funcionário em empresa privada & 12 & $12 \%$ & $94 \%$ & 11 & $27 \%$ & $93 \%$ \\
\hline Empresário ou sócio & 1 & $1 \%$ & $95 \%$ & 2 & $5 \%$ & $98 \%$ \\
\hline Outro & 5 & $5 \%$ & $100 \%$ & 1 & $2 \%$ & $100 \%$ \\
\hline Total & 99 & $100 \%$ & - & 41 & $100 \%$ & - \\
\hline
\end{tabular}

Fonte: dados primários

Quando questionados sobre como eles planejam suas carreiras, 35\% dos ingressos responderam que não fazem um planejamento de carreira, já nos egressos estes números representam $12 \%$, isso pode indicar esses estudantes percebem a necessidade de planejarem suas carreiras mais próximo do final da vida acadêmica, quando estão prestes a entrar no mercado de trabalho. 


\section{A IMPORTÂNCIA DAS ATIVIDADES EXTRACURRICULARES UNIVERSITÁRIAS PARA O ALCANCE DOS OBJETIVOS PROFISSIONAIS DOS ALUNOS DE ADMINISTRAÇÃO DA UNIVERSIDADE FEDERAL DE SANTA CATARINA}

Tabela 2: Elaboração do planejamento de carreira

\begin{tabular}{|c|c|c|c|c|c|c|}
\hline \multirow[t]{2}{*}{ De que forma você faz o seu planejamento de carreira? } & $\begin{array}{c}\text { Frequência } \\
\text { absoluta }\end{array}$ & $\begin{array}{c}\text { Frequência } \\
\text { relativa }\end{array}$ & \begin{tabular}{|c|} 
Frequência \\
relativa \\
acumulada \\
\end{tabular} & $\begin{array}{c}\text { Frequência } \\
\text { absoluta }\end{array}$ & $\begin{array}{c}\text { Frequência } \\
\text { relativa }\end{array}$ & $\begin{array}{l}\text { Frequência } \\
\text { relativa } \\
\text { acumulada }\end{array}$ \\
\hline & \multicolumn{3}{|c|}{ Ingressos } & \multicolumn{3}{|c|}{ Egressos } \\
\hline Não tenho planejamento de carreira & 35 & $35 \%$ & $35 \%$ & 5 & $12 \%$ & $12 \%$ \\
\hline Tenho definido os meus objetivos profissionais e sei em que p & 58 & $59 \%$ & $94 \%$ & 29 & $71 \%$ & $83 \%$ \\
\hline Já tenho meu planejamento, inclusive utilizo um software espe & 1 & $1 \%$ & $95 \%$ & 0 & $0 \%$ & $83 \%$ \\
\hline Tenho um planejamento de carreira e utilizo softwares como & 5 & $5 \%$ & $100 \%$ & 7 & $17 \%$ & $100 \%$ \\
\hline Outro & 0 & $0 \%$ & $100 \%$ & 0 & $0 \%$ & $100 \%$ \\
\hline Total & 99 & $100 \%$ & - & 41 & $100 \%$ & - \\
\hline
\end{tabular}

Fonte: dados primários

Percebe-se que além de apresentarem um percentual menor de respondentes que não tem plano de carreira, os egressos também o atualizam com mais freqüência, como pode-se observar nas tabelas 2 e 3 .

Tabela 3: Atualização do planejamento de carreira

\begin{tabular}{|c|c|c|c|c|c|c|}
\hline \multirow[t]{2}{*}{ Com que frequência você atualiza o seu plano de carreira? } & $\begin{array}{c}\text { Frequência } \\
\text { absoluta }\end{array}$ & $\begin{array}{c}\text { Frequência } \\
\text { relativa }\end{array}$ & $\begin{array}{c}\text { Frequência } \\
\text { relativa } \\
\text { acumulada }\end{array}$ & $\begin{array}{c}\text { Frequência } \\
\text { absoluta }\end{array}$ & $\begin{array}{c}\text { Frequência } \\
\text { relativa }\end{array}$ & $\begin{array}{l}\text { Frequência } \\
\text { relativa } \\
\text { acumulada }\end{array}$ \\
\hline & \multicolumn{3}{|c|}{ Ingressos } & \multicolumn{3}{|c|}{ Egressos } \\
\hline Não tenho um planejamento de carreira & 41 & $41 \%$ & $41 \%$ & 10 & $24 \%$ & $24 \%$ \\
\hline Mensalmente & 11 & $11 \%$ & $53 \%$ & 6 & $15 \%$ & $39 \%$ \\
\hline Trimestralmente & 3 & $3 \%$ & $56 \%$ & 4 & $10 \%$ & $49 \%$ \\
\hline Semestralmente & 10 & $10 \%$ & $66 \%$ & 8 & $20 \%$ & $68 \%$ \\
\hline Anualmente & 4 & $4 \%$ & $70 \%$ & 1 & $2 \%$ & $71 \%$ \\
\hline Esporadicamente & 28 & $28 \%$ & $98 \%$ & 11 & $27 \%$ & $98 \%$ \\
\hline Não respondeu & 2 & $2 \%$ & $100 \%$ & 1 & $2 \%$ & $100 \%$ \\
\hline Total & 99 & $100 \%$ & - & 41 & $100 \%$ & - \\
\hline
\end{tabular}

Fonte: dados primários

Observa-se na tabela 4 que existe uma contradição quando compara-se os dados da tabela 2 e da tabela 2: quando questionados sobre a importância de um planejamento de carreira, apesar da maioria dos alunos pesquisados responderem que não elaboram seus planos de carreira, a grande maioria alega que considera importante ou muito importante têlo.

Tabela 4: Importância do planejamento de carreira

\begin{tabular}{|c|c|c|c|c|c|c|}
\hline \multirow[t]{2}{*}{$\begin{array}{c}\text { Qual é a importância de um planejamento de carreira para } \\
\text { você? }\end{array}$} & $\begin{array}{l}\text { Frequência } \\
\text { absoluta }\end{array}$ & $\begin{array}{l}\text { Frequência } \\
\text { relativa }\end{array}$ & $\begin{array}{c}\text { Frequência } \\
\text { relativa } \\
\text { acumulada }\end{array}$ & $\begin{array}{c}\text { Frequência } \\
\text { absoluta }\end{array}$ & $\begin{array}{l}\text { Frequência } \\
\text { relativa }\end{array}$ & $\begin{array}{l}\text { Frequência } \\
\text { relativa } \\
\text { acumulada }\end{array}$ \\
\hline & \multicolumn{3}{|c|}{ Ingressos } & \multicolumn{3}{|c|}{ Egressos } \\
\hline Não importante & 1 & $1 \%$ & $1 \%$ & 0 & $0 \%$ & $0 \%$ \\
\hline Pouco importante & 5 & $5 \%$ & $6 \%$ & 2 & $5 \%$ & $5 \%$ \\
\hline Sou indiferente & 14 & $14 \%$ & $20 \%$ & 2 & $5 \%$ & $10 \%$ \\
\hline Importante & 55 & $56 \%$ & $76 \%$ & 24 & $59 \%$ & $68 \%$ \\
\hline Muito importante & 24 & $24 \%$ & $100 \%$ & 13 & $32 \%$ & $100 \%$ \\
\hline Total & 99 & $100 \%$ & - & 41 & $100 \%$ & - \\
\hline
\end{tabular}

Fonte: dados primários

Rev. GUAL., Florianópolis, Edição especial 2011, p.163-194. 
Conforme o cruzamento de dados realizado, dos ingressos que responderam não terem um plano de carreira:

- $54,29 \%$ acham que um plano de carreira é importante;

- $2,86 \%$ consideram muito importante;

- $31,43 \%$ são indiferentes;

- $8,57 \%$ consideram pouco importante; e

- $2,86 \%$ não considera importante.

Ou seja, mesmo não tendo um plano de carreira, os ingressos consideram importante elaborá-lo. Sugere-se uma pesquisa com mais profundidade em relação ao motivo pelo qual esses estudantes, apesar de considerarem o planejamento de carreira importante ou muito importante, não o elaboram para guiar suas próprias carreiras. Este dado pode revelar falta de informação acerca das atividades extra-curriculares que podem ser desenvolvidas durante a vida acadêmica para desenvolver a carreira. Neste caso, a instituição de ensino poderia rever as suas ações nesse sentido.

Visando identificar as atividades extra-curriculares que esses estudantes consideram importantes para o alcance dos seus objetivos profissionais, nota-se, na tabela 5, que é possível identificar uma forte correlação entre o que os ingressos consideram importante e o que os egressos pretendiam realizar durante o curso de administração, sendo que estudar idiomas é a atividade com a maior importância em todas as perspectivas.

Tabela 5: Importância e pretensão em realizar atividades extra-curriculares

\begin{tabular}{|c|c|c|c|c|c|c|c|c|}
\hline \multirow{3}{*}{$\begin{array}{c}\text { Quais são as atividades extra-curriculares que você } \\
\text { pretende(ingresso)/pretendia(egresso) fazer durante a } \\
\text { graduação porque as julga importantes para os seus objetivos } \\
\text { profissionais? }\end{array}$} & $\begin{array}{c}\text { Frequência } \\
\text { absoluta }\end{array}$ & $\begin{array}{c}\text { Frequência } \\
\text { relativa }\end{array}$ & $\begin{array}{c}\text { Frequência } \\
\text { absoluta }\end{array}$ & $\begin{array}{c}\text { Frequência } \\
\text { relativa }\end{array}$ & $\begin{array}{c}\text { Frequência } \\
\text { absoluta }\end{array}$ & $\begin{array}{l}\text { Frequência } \\
\text { relativa }\end{array}$ & $\begin{array}{c}\text { Frequência } \\
\text { absoluta }\end{array}$ & $\begin{array}{c}\text { Frequência } \\
\text { relativa }\end{array}$ \\
\hline & \multicolumn{2}{|c|}{ Considera importante } & \multicolumn{2}{|c|}{ Prentede realizar } & \multicolumn{2}{|c|}{ Pretendia realizar } & \multicolumn{2}{|c|}{ Realizou } \\
\hline & \multicolumn{2}{|c|}{ Ingressos } & \multicolumn{2}{|c|}{ Ingressos } & \multicolumn{2}{|c|}{ Egressos } & \multicolumn{2}{|c|}{ Egressos } \\
\hline Estágio & 68 & $69 \%$ & 69 & $70 \%$ & 30 & $73 \%$ & 34 & $83 \%$ \\
\hline Intercâmbio acadêmico & 55 & $56 \%$ & 52 & $53 \%$ & 26 & $63 \%$ & 13 & $32 \%$ \\
\hline Intercâmbio profissional & 41 & $41 \%$ & 35 & $35 \%$ & 21 & $51 \%$ & 13 & $32 \%$ \\
\hline Fundar uma empresa & 11 & $11 \%$ & 11 & $11 \%$ & 5 & $12 \%$ & 5 & $12 \%$ \\
\hline Viagem técnica & 26 & $26 \%$ & 26 & $26 \%$ & 18 & $44 \%$ & 21 & $51 \%$ \\
\hline Trabalhar para uma empresa & 50 & $51 \%$ & 39 & $39 \%$ & 16 & $39 \%$ & 22 & $54 \%$ \\
\hline Empresa júnior & 34 & $34 \%$ & 33 & $33 \%$ & 18 & $44 \%$ & 8 & $20 \%$ \\
\hline AIESEC & 11 & $11 \%$ & 11 & $11 \%$ & 5 & $12 \%$ & 6 & $15 \%$ \\
\hline Estudar idiomas & 79 & $80 \%$ & 71 & $72 \%$ & 35 & $85 \%$ & 28 & $68 \%$ \\
\hline Participação em eventos, congressos e conferências & 52 & $53 \%$ & 41 & $41 \%$ & 30 & $73 \%$ & 29 & $71 \%$ \\
\hline Bolsista ou monitoria & 15 & $15 \%$ & 11 & $11 \%$ & 8 & $20 \%$ & 7 & $17 \%$ \\
\hline Iniciação cientifica & 13 & $13 \%$ & 12 & $12 \%$ & 10 & $24 \%$ & 3 & $7 \%$ \\
\hline Publicação de artigos & 17 & $17 \%$ & 16 & $16 \%$ & 16 & $39 \%$ & 7 & $17 \%$ \\
\hline Outros & 5 & $5 \%$ & 8 & $8 \%$ & 0 & $0 \%$ & 1 & $2 \%$ \\
\hline Não respondeu & 2 & $2 \%$ & 5 & $5 \%$ & 1 & $2 \%$ & 1 & $2 \%$ \\
\hline Total & 99 & - & 99 & - & 41 & - & 41 & - \\
\hline
\end{tabular}

Fonte: dados primários

Rev. GUAL., Florianópolis, Edição especial 2011, p.163-194. 


\section{A IMPORTÂNCIA DAS ATIVIDADES EXTRACURRICULARES UNIVERSITÁRIAS PARA O ALCANCE DOS OBJETIVOS PROFISSIONAIS DOS ALUNOS DE ADMINISTRAÇÃO DA UNIVERSIDADE FEDERAL DE SANTA CATARINA}

A participação em eventos, congressos e conferências foi a atividade que teve a maior diferença entre os ingressos e egresso: enquanto $73 \%$ dos egressos participaram desse tipo de atividade, somente $53 \%$ dos ingressos consideram importante essa atividade. A iniciação científica e a publicação de artigos obtiveram uma porcentagem relevante quando se analisa o que os egressos pretendiam realizar, $24 \%$ e $39 \%$, respectivamente. Porém, somente $7 \%$ (ingressos) e $17 \%$ (egressos) realizaram essas atividades e, para os ingressos, essas duas atividades não são consideradas muito importantes, tendo em vista que somente $13 \%$ considera importante a iniciação científica e $17 \%$ a publicação de artigos.

A seguir, apresentam-se os mini-cursos que esses estudantes gostariam que a instituição de ensino oferecessem. Alem das respostas que foram apresentadas, por serem as mais comuns para esse público, foram também apresentadas no campo "outros" os seguintes mini-curso: a) como apresentar um projeto para uma empresa contratante; b) como utilizar a calculadora; c) algum curso relacionado à tributação brasileira; d) resolução de cases; e) oportunidades de carreiras; f) negociação e vendas; g) pacote Office; h) melhorar a assertividade em geral; i) investimento na bolsa de valores e; j) cursos de qualidade. Entretanto, apesar de vários alunos demonstrarem interesse por esses mini-cursos, um respondente afirmou que oferecê-los não é responsabilidade do departamento, mas sim do Centro Acadêmico do curso de Administração (CAAD). Caberia uma análise entre o departamento do curso e o CAAD para que se verificasse quais poderiam ser as responsabilidades de cada um para suprir essa necessidade dos estudantes. Apresenta-se abaixo a tabela 6 com os resultados dessa pergunta.

Tabela 6: Interesse em mini-cursos

\begin{tabular}{l|c|c|c|c}
\hline \multirow{2}{*}{$\begin{array}{c}\text { Quais dos minicursos descritos abaixo, voce gostaria que o } \\
\text { departamento de administração oferesse: }\end{array}$} & $\begin{array}{c}\text { Frequência } \\
\text { absoluta }\end{array}$ & $\begin{array}{c}\text { Frequência } \\
\text { relativa }\end{array}$ & $\begin{array}{c}\text { Frequência } \\
\text { absoluta }\end{array}$ & $\begin{array}{c}\text { Frequência } \\
\text { relativa }\end{array}$ \\
\cline { 2 - 5 } Como elaborar um curriculo & 38 & $38 \%$ & 15 & $37 \%$ \\
Como se preparar para uma entrevista/dinâmica & 49 & $49 \%$ & 21 & $51 \%$ \\
Como falar em público & 73 & $74 \%$ & 27 & $66 \%$ \\
Outros & 21 & $21 \%$ & 9 & $22 \%$ \\
\hline Total & $\mathbf{9 9}$ & $\mathbf{1 0 0 \%}$ & $\mathbf{4 1}$ & $\mathbf{1 0 0 \%}$ \\
\hline
\end{tabular}

Fonte: dados primários

Rev. GUAL., Florianópolis, Edição especial 2011, p.163-194. 


\section{A IMPORTÂNCIA DAS ATIVIDADES EXTRACURRICULARES UNIVERSITÁRIAS PARA O ALCANCE DOS OBJETIVOS PROFISSIONAIS DOS ALUNOS DE ADMINISTRAÇÃO DA UNIVERSIDADE FEDERAL DE SANTA CATARINA}

O interesse em que o departamento de administração ofereça mini-cursos foi grande para os ingressos e para os egressos, sendo que o mini-curso com a maior interesse foi o de como falar em público com $74 \%$ e $66 \%$ dos ingressos e egressos, respectivamente. Todos os outros cursos apresentam uma porcentagem relevante, sendo que o curso de como se preparar para uma entrevista/dinâmica desperta o interesse de $49 \%$ e $51 \%$ dos ingressos e egressos respectivamente.

Quando questionados sobre outras atividades ou eventos que poderia ser oferecidos pela universidade, percebe-se que há uma grande interesse novamente pelo planejamento de carreira e também por feiras de emprego, como pode-se observar na tabela 7 apresentada a seguir.

Tabela 7: Interesse em atividades complementares para empregabilidade

\begin{tabular}{l|cc|c|c|c}
\hline \multirow{2}{*}{$\begin{array}{c}\text { Dentre as atividades descritas abaixo, assinale quais voce } \\
\text { considera importante o departamento de administração } \\
\text { ofereça: }\end{array}$} & $\begin{array}{c}\text { Frequência } \\
\text { absoluta }\end{array}$ & $\begin{array}{c}\text { Frequência } \\
\text { relativa }\end{array}$ & $\begin{array}{c}\text { Frequência } \\
\text { absoluta }\end{array}$ & $\begin{array}{c}\text { Frequência } \\
\text { relativa }\end{array}$ \\
\cline { 2 - 6 } Feira de emprego & 45 & $45 \%$ & 28 & $68 \%$ \\
Acompanhamento individual de carreira por uma equipe espe & 37 & $37 \%$ & 22 & $54 \%$ \\
Mini-cursos na área de planejamento de carreira & 65 & $66 \%$ & 25 & $61 \%$ \\
Outros & 4 & $4 \%$ & 1 & $2 \%$ \\
\hline Total & $\mathbf{9 9}$ & $\mathbf{1 0 0} \%$ & $\mathbf{4 1}$ & $\mathbf{1 0 0 \%}$ \\
\hline
\end{tabular}

Fonte: dados primários

A importância do departamento de administração oferecer atividades como Minicursos na área de planejamento de carreira é percebida por $66 \%$ do ingressos entrevistados e $61 \%$ dos egressos entrevistados, Já a realização de Feiras de empregos, 45\% dos ingressos consideram importante, sendo que $68 \%$ dos egressos dão importância a tal atividade, e uma diferença parecida de percepção ocorre na atividade de acompanhamento individual de carreira que somente $37 \%$ dos ingressos consideraram importante, já entre os egressos 54\% consideram essa atividade importante.

Enquanto na tabela 5 apresentou-se os resultados sobre o que esses alunos pretendem realizar ou já realizaram, na tabela 8 apresenta-se os resultados em relação à importância de cada atividade extra-curricular para o alcance dos seus objetivos profissionais. Compreendese que, apesar de o aluno considerar importante uma determinada atividade, ele pode não pretender realizá-la por diversos motivos. Um exemplo disso seria, apesar de um estudante

Rev. GUAL., Florianópolis, Edição especial 2011, p.163-194. 
considerar o intercâmbio acadêmico importante, ele pode não poder realizá-lo por não apresentar condições financeiras para tal ou não poder largar o seu emprego atual para uma viagem ao exterior. A seguir, na tabela 8 , são apresentadas os resultados sobre o grau de importância de cada atividade para esses alunos.

\begin{tabular}{|c|c|c|c|c|c|c|c|c|c|c|}
\hline \multirow{2}{*}{$\begin{array}{l}\text { Classifique em ordem de importância as atividades extra- } \\
\text { curriculares que você considera que contribuirão para o alcance } \\
\text { dos seus objetivos profissionais? }\end{array}$} & \multicolumn{5}{|c|}{ Ingressos } & \multicolumn{5}{|c|}{ Egressos } \\
\hline & \begin{tabular}{|c|} 
Não \\
considero \\
importante
\end{tabular} & $\begin{array}{c}\text { Pouco } \\
\text { importante }\end{array}$ & \begin{tabular}{c|} 
Sou \\
indiferente
\end{tabular} & Importante & $\begin{array}{c}\text { Muito } \\
\text { importante }\end{array}$ & \begin{tabular}{|c|} 
Não \\
considero \\
importante
\end{tabular} & $\begin{array}{c}\text { Pouco } \\
\text { importante }\end{array}$ & \begin{tabular}{|c|} 
Sou \\
indiferente
\end{tabular} & Importante & $\begin{array}{c}\text { Muito } \\
\text { importante }\end{array}$ \\
\hline Estágio & 0 & 6 & 11 & 45 & 37 & 2 & 2 & 4 & 15 & 18 \\
\hline Intercâmbio acadêmico & 3 & 5 & 15 & 44 & 32 & 1 & 2 & 3 & 19 & 16 \\
\hline Intercâmbio profissional & 1 & 3 & 21 & 42 & 32 & 2 & 0 & 6 & 16 & 17 \\
\hline Fundar uma empresa & 5 & 15 & 43 & 22 & 14 & 4 & 3 & 23 & 5 & 6 \\
\hline Viagem técnica & 4 & 7 & 37 & 44 & 7 & 2 & 3 & 11 & 21 & 4 \\
\hline Trabalhar para uma empresa & 1 & 0 & 16 & 52 & 30 & 1 & 1 & 5 & 21 & 13 \\
\hline Empresa júnior & 8 & 3 & 30 & 39 & 19 & 2 & 6 & 12 & 17 & 4 \\
\hline AIESEC & 6 & 4 & 47 & 31 & 11 & 4 & 3 & 18 & 12 & 4 \\
\hline Estudar idiomas & 0 & 0 & 9 & 37 & 53 & 0 & 0 & 0 & 19 & 22 \\
\hline Participação em eventos, congressos e conferências & 1 & 3 & 22 & 52 & 21 & 1 & 3 & 8 & 20 & 9 \\
\hline Bolsista ou monitoria & 5 & 12 & 42 & 32 & 8 & 8 & 5 & 15 & 9 & 4 \\
\hline Iniciação cientifica & 7 & 13 & 42 & 27 & 10 & 7 & 2 & 12 & 16 & 4 \\
\hline Publicação de artigos & 8 & 14 & 38 & 29 & 10 & 6 & 4 & 15 & 8 & 8 \\
\hline
\end{tabular}

Fonte: dados primín

Estudar idiomas continua como a atividade extra-curricular mais importante tanto para os estudantes que entraram em 2010 no curso de administração da UFSC quanto para os alunos que estão se formando no mesmo curso. Logo após observa-se o Estágio, com 37\% dos estudantes ingressos considerando muito importante essa atividade e $44 \%$ dos estudantes egressos que compartilham da mesma opinião. Apenas $20 \%$ dos estudantes ingressantes consideram pouco importante ou não consideram importante participar da fundação de uma empresa, enquanto $73 \%$ dos estudantes egressos se dizem indiferente, ou consideram pouco importante ou não consideram importante tal atividade.

Os resultados apresentados podem revelar que o empreendedorismo não é uma atividade apreciada por esses estudantes. Questiona-se portanto a formação desses alunos para serem gerentes e não empresários, tendo em vista que o curso pesquisado forma administradores de empresas. Deveria o curso incentivar mais o empreendedorismo entre esses alunos?

A seguir, na tabela 9 são apresentados os resultados em relação aos objetivos profissionais desses estudantes apos o termino da graduação. Dos 35 ingressos que responderam que após se formarem querem continuar os estudos (pós-graduação, mestrado, outra graduação, etc.): apenas 7 declaram que pretendem publicar artigos durante a graduação.

Rev. GUAL., Florianópolis, Edição especial 2011, p.163-194. 
Destes 7, apenas 3 pretendem além de publicar artigos realizar bolsa, monitoria ou programa de iniciação cientifica,que são essenciais para o objetivo "fazer mestrado". Assim, percebe-se uma incongruência nas respostas, que pode ser falta de informação sobre a importância das atividades disponíveis.

\begin{tabular}{|c|c|c|c|c|c|c|}
\hline \multirow[t]{2}{*}{$\begin{array}{l}\text { Qual o seu objetivo profissional após o término da } \\
\text { graduação? }\end{array}$} & $\begin{array}{c}\text { Frequência } \\
\text { absoluta }\end{array}$ & $\begin{array}{l}\text { Frequência } \\
\text { relativa }\end{array}$ & $\begin{array}{c}\text { Frequência } \\
\text { relativa } \\
\text { acumulada }\end{array}$ & $\begin{array}{c}\text { Frequência } \\
\text { absoluta }\end{array}$ & $\begin{array}{c}\text { Frequência } \\
\text { relativa }\end{array}$ & $\begin{array}{l}\text { Frequência } \\
\text { relativa } \\
\text { acumulada }\end{array}$ \\
\hline & \multicolumn{3}{|c|}{ Ingressos } & \multicolumn{3}{|c|}{ Egressos } \\
\hline $\begin{array}{l}\text { Continuar os estudos (pós-graduação, outras graduações, } \\
\text { mestrado, especialização e etc) }\end{array}$ & 35 & $35 \%$ & $35 \%$ & 11 & $27 \%$ & $27 \%$ \\
\hline Dar continuidade aos negócios da familia & 6 & $6 \%$ & $41 \%$ & 5 & $12 \%$ & $39 \%$ \\
\hline Prestar concurso público ou trabalhar em emprego público & 16 & $16 \%$ & $58 \%$ & 6 & $15 \%$ & $54 \%$ \\
\hline $\begin{array}{l}\text { Fundar uma empresa ou continuar trabalhando na } \\
\text { empresa que fundou }\end{array}$ & 16 & $16 \%$ & $74 \%$ & 7 & $17 \%$ & $71 \%$ \\
\hline Trabalhar para uma empresa & 17 & $17 \%$ & $91 \%$ & 9 & $22 \%$ & $93 \%$ \\
\hline Ir para o exterior & 9 & $9 \%$ & $100 \%$ & 3 & $7 \%$ & $100 \%$ \\
\hline Outro & 0 & $0 \%$ & $100 \%$ & 0 & $0 \%$ & $100 \%$ \\
\hline Total & 99 & $100 \%$ & - & 41 & $100 \%$ & - \\
\hline
\end{tabular}

Fonte: dados primários

A partir dos dados coletados sobre o objetivo profissional após o término da graduação é possível observar uma distinção entre os ingressos e os egressos na escolha de seu objetivo, pois enquanto $35 \%$ dos ingressos pretendem continuar os estudos, $27 \%$ dos egressos responderam que tem o mesmo objetivo. E para $22 \%$ dos egressos o objetivo após a graduação é trabalhar para uma empresa, enquanto para os ingressos $17 \%$ responderam que compartilham do mesmo objetivo.

Tabela 10: Fatores determinantes para a escolha dos objetivos profissionais

\begin{tabular}{l|cc|c|c|c}
\hline \multirow{2}{*}{$\begin{array}{c}\text { Assinale os fatores que foram determinantes para sua } \\
\text { escolha por esses objetivos profissionais? }\end{array}$} & $\begin{array}{c}\text { Frequênc } \\
\text { ia } \\
\text { absoluta }\end{array}$ & $\begin{array}{c}\text { Frequênc } \\
\text { ia } \\
\text { relativa }\end{array}$ & $\begin{array}{c}\text { Frequênc } \\
\text { ia } \\
\text { absoluta }\end{array}$ & $\begin{array}{c}\text { Frequênc } \\
\text { ia } \\
\text { relativa }\end{array}$ \\
\cline { 2 - 6 } Ingressos & \multicolumn{2}{|c|}{ Egressos } \\
\hline ambiente (cultura, economia e etc) & 39 & $39 \%$ & 24 & $59 \%$ \\
Antigas experiências profissionais & 14 & $14 \%$ & 8 & $20 \%$ \\
Influência de familiars / amigos & 30 & $30 \%$ & 13 & $32 \%$ \\
Influência de professores e colegas & 9 & $9 \%$ & 0 & $0 \%$ \\
Minhas habilidades e competências & 55 & $56 \%$ & 32 & $78 \%$ \\
Possibilidade de remuneração adequada & 46 & $46 \%$ & 23 & $56 \%$ \\
Escolha se enquadra melhor com meus objetivos pessoais & 51 & $52 \%$ & 22 & $54 \%$ \\
Influência da experiência que tive na universidade & 15 & $15 \%$ & 2 & $5 \%$ \\
Outro & 4 & $4 \%$ & 0 & $0 \%$ \\
\hline Total & 99 & $100 \%$ & 41 & $100 \%$ \\
\hline Fonte: dados primários
\end{tabular}

Rev. GUAL., Florianópolis, Edição especial 2011, p.163-194. 


\section{A IMPORTÂNCIA DAS ATIVIDADES EXTRACURRICULARES UNIVERSITÁRIAS PARA O ALCANCE DOS OBJETIVOS PROFISSIONAIS DOS ALUNOS DE ADMINISTRAÇÃO DA UNIVERSIDADE FEDERAL DE SANTA CATARINA}

Para $78 \%$ dos estudantes egressos as suas habilidades e competências foram os fatores determinantes para a sua escolha do objetivo profissional, já $56 \%$ dos ingressos responderam que esse mesmo fator foi determinante para sua escolha. A influência de professores e colegas foram os fatores que menos influenciaram tanto os ingressos quanto os egressos. E o enquadramento com os objetivos pessoais e a influência de familiares e amigos foram dois objetivos que os ingressos e egressos assinalaram com a mesma frequência percentual.

Tabela 11: Faixa etária

\begin{tabular}{l|c|c|c|c|c|c}
\hline \multirow{2}{*}{ Qual a sua faixa etária? } & $\begin{array}{c}\text { Frequência } \\
\text { absoluta }\end{array}$ & $\begin{array}{c}\text { Frequência } \\
\text { relativa }\end{array}$ & $\begin{array}{c}\text { Frequência } \\
\text { relativa } \\
\text { acumulada }\end{array}$ & $\begin{array}{c}\text { Frequência } \\
\text { absoluta }\end{array}$ & $\begin{array}{c}\text { Frequência } \\
\text { relativa }\end{array}$ & $\begin{array}{c}\text { Frequência } \\
\text { relativa } \\
\text { acumulada }\end{array}$ \\
\cline { 2 - 7 } Ingressos & \multicolumn{3}{c}{ Egressos } \\
\hline 16 a 20 anos & 67 & $68 \%$ & $68 \%$ & 0 & $0 \%$ & $0 \%$ \\
21 a 25 anos & 21 & $21 \%$ & $89 \%$ & 31 & $76 \%$ & $76 \%$ \\
26 a 30 anos & 8 & $8 \%$ & $97 \%$ & 8 & $20 \%$ & $95 \%$ \\
31 a 35 anos & 2 & $2 \%$ & $99 \%$ & 2 & $5 \%$ & $100 \%$ \\
Mais de 35 anos & 1 & $1 \%$ & $100 \%$ & 0 & $0 \%$ & $100 \%$ \\
\hline Total & 99 & $100 \%$ & - & 41 & $100 \%$ & - \\
\hline
\end{tabular}

Fonte: dados primários

Dentre os estudantes pesquisados, $96,4 \%$ tem menos que 30 anos de idade, sendo que entre os ingressos $89 \%$ tem menos que 25 anos e entre os egressos essa mesma faixa etária acumula uma frequência absoluta de $76 \%$.

As pessoas podem marcar mais de uma caixa de seleção, então a soma das percentagens pode ultrapassar $100 \%$. Em relação a trabalhar para uma empresa, apenas 17\% dos ingressos responderam que após se formarem gostariam de trabalhar para uma empresa, contra $27 \%$ dos egressos que responderam que trabalham em uma empresa. Dos ingressos, $16 \%$ responderam que gostariam de fundar uma empresa u continuar na empresa que fundou, porém apenas $5 \%$ dos egressos responderam que são empresários ou sócios e $7 \%$ são profissionais liberais.

Outra informação que pode ser verificada que coincidem em expectativas dos ingressos e a realidade dos egressos é a questão do concurso publico, já que $16 \%$ dos ingressos declaram que tem como objetivos prestar concurso público e $15 \%$ dos egressos são funcionários públicos.

Rev. GUAL., Florianópolis, Edição especial 2011, p.163-194. 


\section{CONSIDERAÇÕES FINAIS}

Este trabalho teve como objetivo analisar identificar como os alunos ingressos e egressos do curso superior de Administração da Universidade Federal de Santa Catarina avaliam a importância do desenvolvimento de atividades extracurriculares durante a vida acadêmica para o alcance dos seus objetivos profissionais. A partir da análise dos dados coletados, concluiu-se que os alunos, tanto ingressos quanto egressos, gostariam que a UFSC oferecesse, mini-cursos sobre planejamento de carreira e oratória. Ainda foi identificado o interesse desses alunos em ter um acompanhamento e orientação de carreira. Constatou-se também que $48 \%$ dos ingressos e $68 \%$ dos egressos gostariam que a universidade desenvolvesse feira de empregos. Desta forma, esta pesquisa apresenta uma visão do que os alunos ingressantes e egressos do curso de administração da UFSC de 2010 estão requerendo de ações da universidade que podem desenvolver suas competências além do conhecimento acadêmico e teórico.

Em relação ao planejamento de carreira, notou-se a falta de orientação desses alunos sobre como selecionar as atividades extra-curriculares que poderão contribuir para o alcance dos seus objetivos profissionais. Através desta pesquisa, percebeu-se que muitos alunos pretendem continuar os estudos além da graduação, porém, uma baixa porcentagem desses estudantes mostrou-se interessado em executar atividades como publicação de artigos científicos, monitoria, bolsa de pesquisa científica, para desenvolver habilidades requeridas pelos níveis mais avançados de estudo.

Considerando os resultados obtidos nessa pesquisa e as informações coletadas sobre outras universidades, sugere-se que a UFSC reveja como poderia atender essas expectativas dos seus alunos, principalmente em um ambiente cada vez mais globalizado e competitivo. $\mathrm{O}$ departamento de Ciências da Administração poderia rever as responsabilidades do Centro Acadêmico do curso de Administração ou poderia também criar um núcleo no Centro SócioEconômico que promova atividades como palestras, cursos, mini-cursos, feiras de empregos relacionadas ao tema planejamento de carreira e desenvolvimento profissional. Ressaltando que é comum centros de desenvolvimento de carreira em universidades no exterior. Um exemplo disso é a University of Nottingham, na Inglaterra, que oferece diversas atividades que foram consideradas importantes para o alcance dos objetivos profissionais dos alunos. Além 


\section{A IMPORTÂNCIA DAS ATIVIDADES EXTRACURRICULARES UNIVERSITÁRIAS PARA O ALCANCE DOS OBJETIVOS PROFISSIONAIS DOS ALUNOS DE ADMINISTRAÇÃO DA UNIVERSIDADE FEDERAL DE SANTA CATARINA}

disso, outras universidades renomadas no Brasil, como a Fundação Getúlio Vargas, também dispõe de um núcleo para o desenvolvimento de carreira.

Espera-se que este estudo sirva de base para a revisão das atividades que o curso da UFSC pode oferecer aos seus alunos apesar de ser uma universidade pública, a qual poderia dispor de menos recursos financeiros que as universidades particulares citadas anteriormente.

Afim de orientar melhor os alunos que ingressam nesse curso, propõe-se a organização de eventos que visem esclarecer aos alunos do curso de Administração quais atividades extracurriculares estão à disposição na UFSC para que eles desenvolvam essas outras habilidades e competências que são requeridas pelo mercado de trabalho e que esteja de acordo com os seus objetivos profissionais. Pode-se ainda promover palestras com alunos do final do curso que podem relatar suas experiências e tirar dúvidas daqueles que iniciam seus caminhos no universo repleto de oportunidades que é uma universidade federal de um dos estados mais desenvolvidos do Brasil.

Apesar de existir um núcleo de planejamento de carreira no curso de Psicologia da UFSC e desse mesmo departamento oferecer a disciplina Planejamento de Carreira a todos os alunos da universidade, essas não são ações voltadas aos alunos de todas as fases, mas somente aos que se encontram no último semestre do curso. Dessa forma, essa disciplina ofertada não permite aos estudantes conhecerem as oportunidades de desenvolvimento oferecidas pela UFSC para que possam escolher como pretender se desenvolver. Também não existe um local ou pessoa à qual os alunos possam recorrer em caso de dúvida em relação ao curso que escolheu, ajuda para se preparar para uma entrevista de emprego ou até mesmo uma orientação sobre como elaborar um curriculum vitae para buscar um estágio ou emprego. Entre as atividades do que poderiam ser oferecidas para a toda universidade ou ao Centro Sócio Econômico, estão: a) organização de feiras de empregos em parceria com pequenas, medias e grandes empresas da região; b) promoção de cursos extra-curriculares oferecidos na universidade; c) formação de um acervo de material didático concernente ao assunto de planejamento profissional e temas relacionados (como fazer currículos, como se portar em entrevistas, etc.) para que fiquem à disposição dos alunos interessados; d) orientação individual de carreira; e) levantamento dos requisitos profissionais e qualificações exigidas pelas melhores empresas do ramo; f) condução de pesquisas que visem identificar possíveis

Rev. GUAL., Florianópolis, Edição especial 2011, p.163-194. 
melhorias e contribuições que possam melhorar a empregabilidade dos alunos formados pela UFSC.

Percebe-se através do levantamento bibliográfico que muitos autores defendem que quem se conhece mais consegue traçar objetivos profissionais de forma mais clara, e se o estudante sabe para onde quer ir, procurar por oportunidades alinhadas a este objetivo contribuir, e muito, para uma vida mais feliz.

\section{REFERÊNCIAS}

BARROS, Aidil J. da S.; LEHFELD, Neide A de S. Fundamentos de metodologia científica: um guia para iniciação científica. 2. ed. São Paulo: Makron Books, 2000.

CASTRO, Claudio de Moura. A prática da pesquisa. 2.ed. São Paulo: Pearson Prentice Hall, 2006.

CERVO, Amado; BERVIAN, Pedro A. Metodologia cientifica. São Paulo: Makron Books, 1996.

CIA DE TALENTOS. Disponível em $<$ http://www.ciadetalentos.com.br/>. Acesso em: 12 out. 2010.

Introdução a teoria geral da administração: edição compacta. 3. ed. rev. e atual. Rio de Janeiro: Elsevier: Campus, 2004.

DUTRA, Joel Souza. Administração de carreiras: uma proposta para repensar a gestão de pessoas. São Paulo: Atlas, 1996.

FRIEDMAN, Thomas L. O mundo é plano: uma breve história do século XXI. 2 ed. 2007

GIL, Antônio Carlos. Métodos e técnicas de pesquisa social. 5. ed. São Paulo: Atlas, 1999.

GIULIANI, Antônio Carlos. Marketing em um ambiente globalizado. São Paulo: Cobra, 2003.

KOTLER, Philip e KELLER, Kevin Lane. Administração de Marketing. 12. ed. São Paulo: Pearson Prentice Hall, 2007.

INEP. Evolução da Educação Superior - Graduação. Disponível em:

$<$ http://www.inep.gov.br/superior/censosuperior/evolucao/evolucao.htm> . Acesso em: 24 out. 2010 .

LACOMBE, Francisco; HEILBORN, Gilberto. Administração: princípios e tendências. São Paulo: Saraiva, 2003. 
LIMA, Miguel; SILBER, Simão D. Gestão de Negócios Internacionais. São Paulo: Saraiva, 2006.

MALSCHITZKY, Nancy. Empregabilidade: um modelo para a instituição de ensino superior orientar e encaminhar a carreira profissional dos acadêmicos. Tese de doutorado, Programa de Pós-Graduação em Engenharia de Produção, Florianópolis, 2004.

MARIOTTO, F.L. Mobilizando Estratégias Emergentes. In: BERTERO, C.O. (Coordenador). Gestão Empresarial - Estratégias Organizacionais. São Paulo: Atlas, 2006.

MATTAR, Fauze Najib. Pesquisa de marketing: edição compacta. 3. ed São Paulo: Atlas, 2001. . Pesquisa de marketing. São Paulo: Atlas, 2005.

MET. Ministério do Trabalho e Emprego - CBO traz novas famílias profissionais. Disponível em: < http://www.mte.gov.br/sgcnoticia.asp?IdConteudoNoticia $=6893 \&$ PalavraChave $=$ cbo $>$. Acesso em: 24 out. 2010.

MINARELLI, Jose Augusto. Empregabilidade: o caminho das pedras. Sao Paulo: Gente, 1995.

MINTZBERG, Henry. Ascensão e queda do planejamento estratégico. São Paulo: Bookman, 2008.

OLIVEIRA, Djalma de Pinho Rebouças de. Plano de carreira: foco no indivíduo : como elaborar e aplicar para ser um profissional de sucesso. São Paulo: Atlas, 2009.

SILBER, Simão Davi. A globalização dos mercados. In: VASCONCELLOS, Marco Antonio;

UFSC. Site Inicial. Disponível em: < http://www.ufsc.br >. Acesso em: 20 out. 2010a.

UFSC. Site de acompanhamento de egressos. Disponível em: $<$ http://www.egressos.ufsc.br/ >. Acesso em: 20 out. $2010 \mathrm{~b}$.

VERGARA, Sylvia Constant. Projetos e relatórios de pesquisa em administração. 9. ed São Paulo: Atlas, 2007.

VERIGUINE, Nadia Rocha. Autoconhecimento e informação profissional: implicações para o processo de planejar a carreira de jovens universitários. Universidade Federal de Santa Catarina. Centro de Filosofia e Ciências Humanas. Programa de Pós-graduação em psicologia. Florianópolis, 2008.

WOOD, M. B. NICKELS, W. G.: Marketing: relacionamentos, qualidade, valor. Rio de Janeiro: LTC, 1999. 


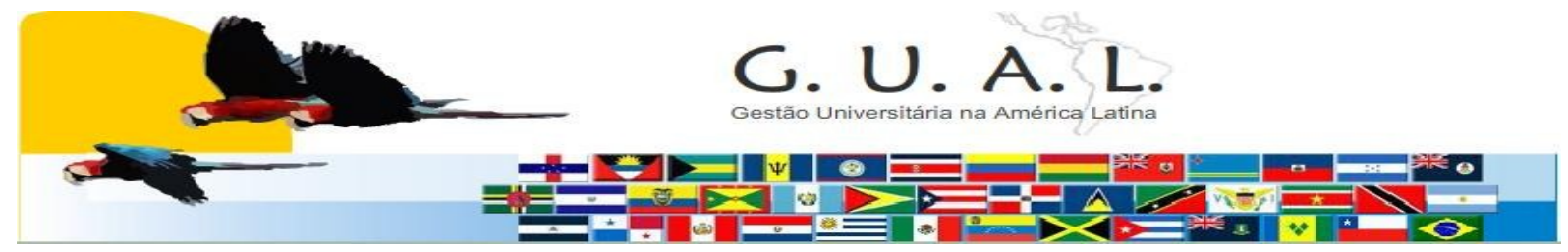

ISSN 1983-4535

\title{
THE IMPORTANCE OF EXTRACURRICULAR ACTIVITIES FOR THE REACH OF PROFESSIONAL GOALS OF THE STUDENTS OF BUSINESS ADMINISTRATION AT THE UNIVERSIDADE FEDERAL DE SANTA CATARINA
}

\author{
Alessandra Knoll Pereira, Specialist \\ Universidade do Vale do Itajai - UNIVALI \\ alekawaii@gmail.com \\ Marcos Fernandes Koshino, Bachelor \\ Universidade Federal de Santa Catarina - UFSC \\ marcoskoshino@gmail.com
}

\author{
Talita Ribeiro Ferreira, Bachelor \\ Universidade Federal de Santa Catarina - UFSC \\ talitaferreira@gmail.com \\ Rudimar Antunes da Rocha, Doctor \\ Universidade Federal de Santa Catarina - UFSC \\ rrudimar@hotmail.com
}

\begin{abstract}
This paper analyzes the importance attributed by students of the Universidade Federal de Santa Catarina to the extracurricular activities in order to reach their professional goals. The general objective was configured as: identify how the students evaluate the importance of extracurricular activities to achieve their professional goals. The specific objectives were: a) identify the extracurricular activities that students consider important for achieving career goals; b) identify the career aspirations of ingress and egress students; c) identify if the ingress and egress students plan their careers; d) explore how the educational institution has been contributing to it by offering extracurricular activities; e) identify which activities are more relevant to help students in the pursuit of professional achievement. This research was classified as descriptive and qualitative, and the method used was literature review and research. The data collection instrument used was printed and online questionnaires. The final findings of this article points to a lack of guidance on choosing the extracurricular activities that could contribute to the achievement of the students' goals, among others conclusions which are presented at the final section of this article.
\end{abstract}

Keywords: Employability. Career planning. University administration. 